\title{
Complex Web Construction: A Possible Clue to Mechanical Properties
}

\author{
L. Pautler ${ }^{1}$, E. Jennings ${ }^{1}$, J. Burnham ${ }^{1}$, T. Swain ${ }^{1}$, C. Li ${ }^{1}$, J. A. Hubbard ${ }^{1}$, N. Moy ${ }^{1}$, D, Shattuck,

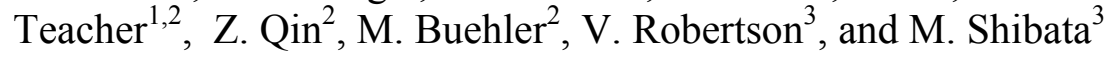 \\ 1. Concord Middle School, Concord, MA, USA \\ 2. Laboratory for Atomistic and Molecular Mechanics, Civil and Environmental Engineering \\ Department, Massachusetts Institute of Technology, Cambridge, MA, USA \\ 3. JEOL USA, Peabody, MA, USA
}

Collaboration among academia, industry, and public education can develop state-of-the-art classroom curricula and real research opportunities for students that were heretofore unavailable in public schools. National initiatives have focused on enhancing the quality of education in Science, Technology, Engineering, and Math (STEM). Massachusetts recently enhanced and adopted new Science and Technology/Engineering Standards based on the national Next Generation Science Standards (NGSS) and placed emphasis on concepts and experience over the more traditional content-based curricula [1].

Materials science has risen to prominence in these standards and students are expected to understand the structure and mechanical properties including strength, stiffness, and response to existence of defects of various materials they encounter in both the natural and human-designed worlds at the macro- meso- and micro-scale as well as understand the dynamic process of how they will responds to forces acting on them. Moreover, these concepts will be incorporated in the comprehensive Science, Technology/Engineering (STE) exam-MCAS-required of all Massachusetts eighth graders by 2018. Unfortunately, most communities are unable or are ill-equipped to provide and support the advanced technology needed to permit middle school students to conduct research into the dynamics of material systems.

Collaborative outreach among academic institutions, and vendors of advanced instruments can offer substantial benefit to public schools. Presented here in poster format are the preliminary results of an investigation conducted by seven middle school students into the mechanical properties of spider webs being studied at MIT's Laboratory for Atomistic and Molecular Mechanics (LAMM) using images and technology provided by JEOL, USA. This program was conducted as part of ongoing cooperative outreach among MIT CEE, LAMM, JEOL USA, and Concord (MA) Middle School. The audience is the middle school introductory engineering student and the poster is intended to summarize student research efforts. Their investigations stems from an observation by Dr. Qin of an unusual repeating pattern in the web of a spider living at MIT. The student study is correlated with and conducted in conjunction with ongoing research by scientists, post docs, graduate students, and visitors at MIT's Laboratory.

This poster begins with a naturally occurring web that consists of rays that emanate from the center and attach the web to its support structure. These lines are in tension and support the dead, live, and environmental loads. Chords or cross threads link the rays to form a familiar net-like web. An optical micrograph presents a web segment made by a "sheet web" producing spider of the Araneidae family harvested at MIT. Micrographic enhancements, provided by JEOL, reveal a unique pattern in which rays of web are connected by chords that helically wrap each ray. At 1000x the complexity of junctions between ray and chord is revealed.

The goal of the investigation was to determine whether the helically wrapped chords in frames 2,3 , and 4 provided any mechanical advantage when it comes to managing normal tensile forces acting on the web. The coiling structure at the junction is geometrically so complex that it could not be printed by a 3D printer and studied as had been done by the collaborators [2-3]. This offers good motivation to conduct the investigation with the current strategy.

Students evaluated several materials and selected common cotton sewing thread to serve as an analogue for spider silk. Prototype looms were 3D printed and an open-sided octagonal design was selected (frame 5). The design allows for weaving the web so as to stress along the radial (Y) axis, the chord (X) axis, or diagonally (X-Y axis). A vertical test apparatus was assembled to support the loom with the unattached member oriented downward so the web could be stressed by the addition of weight (Frame 6).

Preliminary results indicate the spider's design may support as much as $25 \%$ more weight than the "tennis racket" weave used as a control. The data also indicate variations among the load bearing capacity of the X, Y, and X-Y (diagonal) 
orientations. The diagonal X-Y appears to distribute the weight over a larger number of threads and provide a greater carrying capacity then either the $\mathrm{X}$ or $\mathrm{Y}$ orientations. We feel our data are consistent with findings of other researchers in the Laboratory [4-6] but warrant further study. Future investigations may focus on enhancing robustness of the apparatus and precision of the protocol. In addition to reinforcing concepts developed during research, this activity dramatically demonstrates the links among public school learning, academic research, and the private sector that supports them [7].

\section{References:}

[1] Massachusetts Department of Elementary and Secondary Education, Draft Revised Science and Technology/Engineering Standards, (January, 2016).

[2] Zhao Qin et al, Nature Communications, (2015).

[3] Zhao Qin, Markus J. Buehler, Nature materials, (2013).

[4] S.W. Cranford et al, Nature 482 (2012), p. 72.

[5] N. Pugno, S. Cranford, M.J. Buehler, Small 9(16) (2013), p. 2747.

[6] Anna Tarakanova, Markus J. Buehler, J. R. Soc. Interface (2012).

[7] The content of this poster was derived from materials research conducted by the Laboratory for Atomistic and Molecular Mechanics at MIT. Micrographs were provided by JEOL, USA as part of their support of the research effort. The student authors acknowledge and thank the Laboratory for Atomistic and Molecular Mechanics at MIT and the educational outreach of JEOL, USA. We also want to acknowledge and thank the Boston Post, Society of American Military Engineers for their encouragement and financial support of this project as well as the staff of the New England District, U.S. Army Corps of Engineers for their encouragement offered through our Educational Partnership.

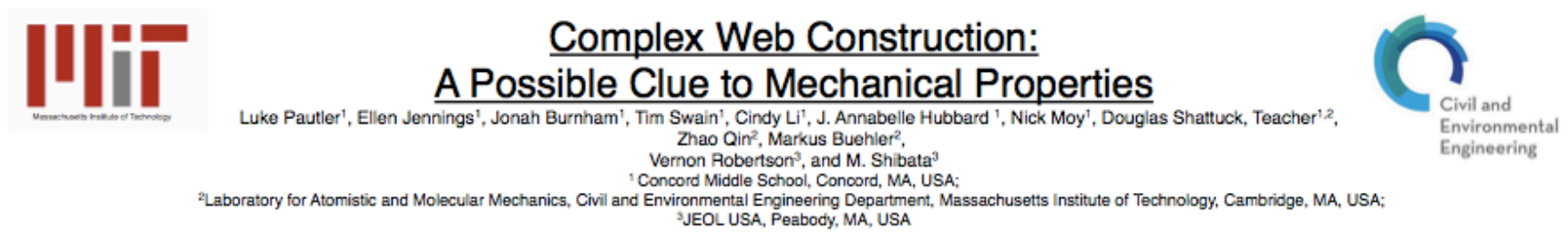

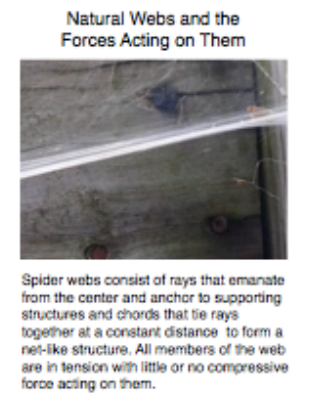

Student Investigation

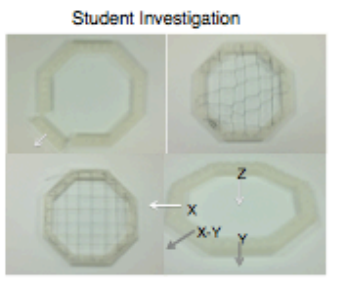

Students evaluated several materias and
expermenta designs to assers the tensile advartage of the spider's web. An octagonal bom Was 30 printed allowing tension to be applied to
craste talure. Dependrig on the cricntaticn of the werve, tensiln could be drawn along the rays ( $(Y)$.

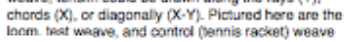
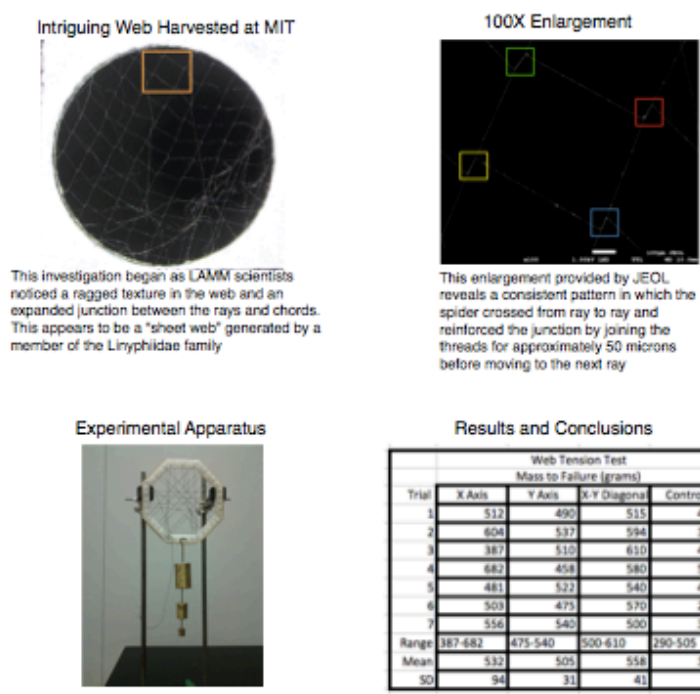

Studerts wave the experimentad and control webs using commercially availebie cotton sewing wead as an anabgus lor the spion

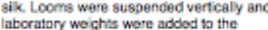
unattached side of the octagan until the web
taled

Preliminary results incicate that the "chord
wrapping" tochnique obse
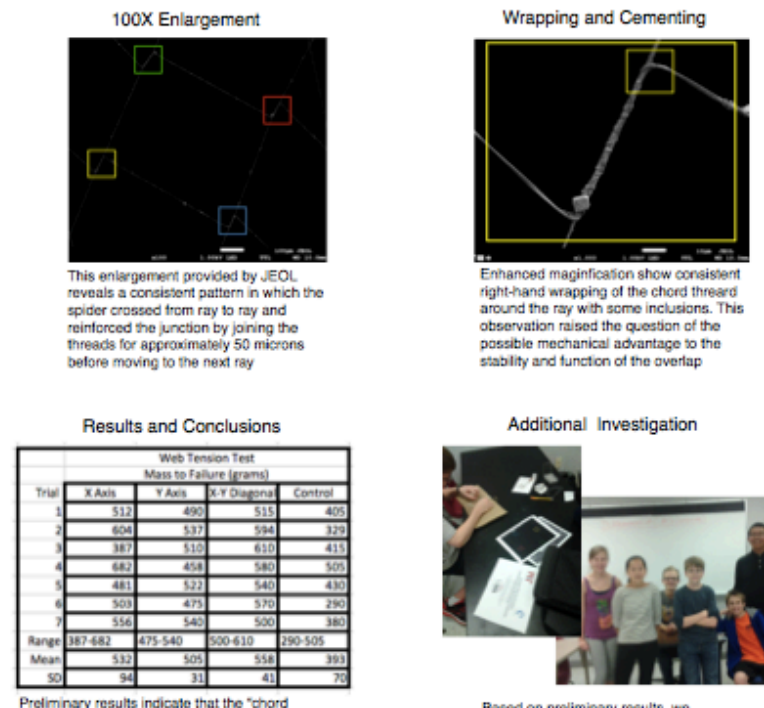

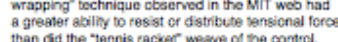

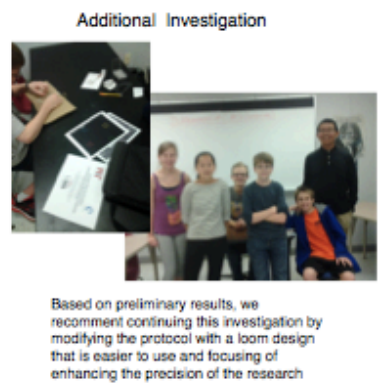

Financial support for this CMS progam was provided by the Basson Potst, Soceosy of Amenican Mittary Engneers, Technical review and encouragemont was provided by staft of the Now
England District, US Ammy Corps of Engineers as part of an Educstiona Parnerghig with Concord Public Sthools. 